\title{
CENTROS LOCAIS E PEQUENAS CIDADES: diferenças necessárias
}

\author{
Prof $^{\mathrm{a}}$. Dr ${ }^{\mathrm{a}}$. Tânia Maria Fresca \\ Departamento de Geociências - UEL \\ Rodovia Celso Garcia Cid, Km 380, Campus Universitário. CEP: 86051980 Londrina (PR), Brasil \\ Tel: (+ 55 43) 33714246 - tania_geografia@yahoo.com.br
}

\begin{abstract}
RESUMO
O trabalho procura contribuir para estabelecer diferenças conceituais entre centros locais e pequenas cidades. Ambos os termos tem sido utilizados em diversas bibliografias como se fossem sinônimos, não levando em conta as necessárias diferenças entre ambos no contexto da urbanização brasileira.
\end{abstract}

Palavras-chave: Centros locais, pequenas cidades, conceitos.

\begin{abstract}
The paper aims to help establish the conceptual differences between local centers and small towns. Both terms have been used in vdiverse bibliographies as if they were synonymous, not taking in account the necessary differences between them in the context of brazilian urbanization.
\end{abstract}

Key words: Local centres, small towns, concepts.

\section{RESUMEN}

El documento tiene como objetivo ayudar a establecer las diferencias conceptuales entre los centros locales y las pequeñas ciudades. Ambos términos han sido utilizados en diferentes bibliografías como si no fueran sinónimos, teniendo en cuenta las diferencias necesarias entre ellos en el contexto de la urbanización brasileña.

Palabras-claves: Centros locales, pequeñas ciudades, conceptos.

\section{INTRODUÇÃO}

Só muito recentemente pesquisadores das mais diversas ciências redescobriram as cidades pequenas e passaram a estudar a importância, o significado e sua representação social, econômica e cultural no contexto da urbanização brasileira. Foi no início dos anos de 1990 que ocorreu certa retomada das discussões sobre redes urbanas e estas cidades, até então pouco privilegiados nas pesquisas geográficas, como fora o trabalho de Fresca (1990). Trabalhos estes que foram realizados a partir da análise da inserção dos núcleos em redes urbanas regionais e proliferaram no contexto das reflexões sobre a necessidade de se estudar cidades de nível não metropolitano. Expandiram-se os estudos sobre as cidades pequenas, haja vista que a intensificação da reestruturação produtiva impôs para estas, outras demandas que possibilitaram o desempenho de novas centralidades no contexto das redes urbanas. E aqui reside um elemento fundamental que defende-se neste trabalho, que é a inserção das cidades pequenas em redes urbanas como caminho profícuo ao seu entendimento.

Esta retomada nos estudos sobre cidades pequenas tem a ver com as intensas modificações na organização sócioespacial brasileira que provocaram transformações em redes urbanas; que permitiram realização de novos papéis nestas cidades; que possibilitaram às mesmas tornarem-se lócus privilegiado da realização de uma parcela da produção propriamente dita; que permitiram a inserção das mesmas em interações espaciais de grande alcance; enfim a redescoberta destas cidades como uma particularidade da urbanização brasileira. 


\section{DIVERSIDADE DE INTERPRETAÇÕES}

Como a preocupação no presente trabalho é contribuir para algumas distinções entre pequenas cidades e centro locais, necessário explicitar algumas questões verificadas em diversos estudos. Quais elementos podem ser utilizados para caracterizar uma cidade como sendo pequena? E a cidade local? A palavra pequena é um adjetivo, que remete à noção de tamanho, dimensão e no caso das cidades, uma associação entre pequeno número de habitantes com pequena área - no sentido mensurável - ocupada por uma cidade. Os termos cidades pequenas e cidades locais, tem sido utilizados em diversas bibliografias como sinônimos, residindo aí um equívoco. Outra situação pouco clara, é quando autores referem a pequenos municípios, como é o caso de Wanderley (2001, p. 4 grifo no original) que procura "[...] refletir sobre os pequenos municípios, entendidos como aqueles cuja população urbana não ultrapassa 20.000 habitantes" cuja análise "[...] das trajetórias de desenvolvimento permite distinguir os municípios preponderantemente urbanos, preponderantemente rurais ou aqueles que correspondem a situações intermediárias" (WANDERLEY, 2001, p. 7).

Ora, pequeno município implica em área territorial e não a sede urbana de cada município, residindo aí mais uma questão de denominação que oculta uma série de situações.

Um dos critérios ainda mais utilizados para delimitar o recorte das pequenas cidades tem sido os dados populacionais. O IBGE (2008) ao analisar a rede urbana nacional estabelece a existência de 4473 centros locais, onde a centralidade é exercida predominantemente em seus limites municipais e caracterizados por terem população inferior a 10 mil habitantes. Mas qual seria o patamar populacional a partir do qual falar-se-ia das pequenas cidades? 20 mil? 50 mil habitantes?

Utilizando-se este caminho para caracterizar uma cidade como sendo pequena, incorre-se no risco de igualar cidades que na sua essência são diferentes. Em outras palavras, o número de habitantes como variável utilizada resultará em considerar cidades com populações similares como sendo pequenas, mas não levará em conta as especificidades de cada uma delas. Não permitirá que se entenda as diferentes inserções de cada núcleo urbano nas redes ou região, impedindo que se entenda seus papéis, suas áreas de influência, suas integrações internas e externas às redes, dentre outros aspectos fundamentais para a consideração de uma cidade como sendo pequena. Evidente que dependendo do estudo e objetivos, nada impede que se utilize o número de habitantes, mas há que se fazer as ressalvas necessárias, acorde aos objetivos estabelecidos na pesquisa.

É o que se verifica com o trabalho de Olanda (2008, p. 187) ao estudar as pequenas cidades no estado de Goiás. Embora vá trabalhar com as noções de concentração e dispersão, acaba por ter nos dados populacionais sua referência para estabelecer quais são as pequenas cidades, aquelas com população inferior a 20 mil habitantes. Mesmo tendo deixado claro a idéia de que número de habitantes em dado contexto territorial, não permite afirmar que a cidade seja pequena, acaba por utilizá-lo. Noção esta presente no artigo de Fresca (2001) que defende a idéia de que a é inserção das mesmas em uma rede urbana e ou região que dará elementos melhores condições para entende-las como tal.

Outra situação que demonstra as dificuldades em trabalhar com esta escala das cidades brasileira, é o estudo de Endlich (2006, p. 52) quando afirma que:

Os pequenos centros urbanos não são iguais entre - si, pois possuem conteúdos diferentes que em alguns casos geram relações hierárquicas entre elas. Cidades com atividades comerciais e equipamentos de serviços públicos e privados um pouco mais diversificados funcionam como pólos microrregionais.

A autora identifica as diferenças entre as pequenas cidades, criando mais uma denominação - pólos microrregionais - na tentativa de dar conta de tão complexo conjunto de centros urbanos, mas não explica teoricamente a diversidade da formação sócioespacial.

A referência a estes trabalhos - que poderiam ser vários outros como Soares (2007), Melo (2006), Oliveira e Soares (2003) - se faz como um caminho para explicitar que por mais qualitativos 
e discutindo inúmeros aspectos e processos que se realizam singularizadamente nestes pequenos núcleos, não há um conjunto de reflexões teóricas que norteiem as pesquisas. Trata-se em suma, da busca de uma construção intelectual que procure dar conta de situações tão diversas.

\section{CIDADES LOCAIS}

A denominação centro local refere-se ao menor escalão das cidades no Brasil - termo este difundido a partir dos estudos sobre redes urbanas tendo na teoria das localidade centrais seu referencial analítico - considera o papel dos centros urbanos de uma rede na distribuição de bens e serviços. A centralidade dos núcleos deriva de seus papéis na distribuição de bens e oferta de serviços, sendo este considerado como o elemento para a análise e o estabelecimento de sua hierarquia.

De acordo com a teoria, a demanda por bens e serviços traduz localizações diferenciadas, pois há produtos e serviços de consumo freqüente e pouco freqüente permitindo estabelecer o alcance espacial máximo e mínimo de cada produto. Desta diferenciação na oferta dos bens e serviços, emerge uma diferenciação entre as localidades centrais, que segundo a teoria, é uma diferenciação de caráter hierárquico. Assim, as localidades de mais baixo nível hierárquico distribuem e ofertam apenas bens e serviços de consumo muito freqüente, sendo estas denominadas de centros locais. No entanto, tal denominação carrega uma variedade de situações, que acabam igualando situações bastante diversas no contexto da formação social brasileira. Da mesma maneira já não é mais possível utilizar este referencial para análise, cujas críticas muitos já o fizeram.

Para tanto, cidade local pode ser entendida a partir da concepção de Santos (1982, p. 71) quando fala da existência de uma dimensão mínima "[...] a partir da qual as aglomerações de população deixam de servir às necessidades da atividade primária, para servir às necessidades inadiáveis da população com verdadeiras especializações do espaço". É preciso que se encontre o fundamento, o limite mínimo de "[...] complexidade das atividades urbanas capazes de [...] garantir ao mesmo tempo um crescimento auto-sustentado e um domínio territorial" (SANTOS, 1982, p. 70). Assim, a cidade local como sendo a de menor complexidade acaba por responder "[...] às necessidades vitais mínimas, reais ou criadas de toda uma população, função esta que implica uma vida de relações" (SANTOS, 1982, p. 71).

\section{PEQUENAS CIDADES}

Para Fresca (2001, p. 28) o posicionamento acima referido, permite entender a dimensão mínima a partir da qual é possível falar de uma verdadeira cidade, e no caso, dos centros locais. Mas isto remete à complexidade das condições e elementos para considerar outras cidades como sendo pequenas. A partir do nível mínimo de atividades acima exposto, há uma diversidade significativa de cidades, cuja complexidade de atividades urbanas extrapola o denominado nível mínimo. Mas isto não gera elementos necessários para que as mesmas possam ser consideradas cidades intermediárias ou metrópoles, significando que mesmo tendo certa complexidade de atividades urbanas acima do nível mínimo, continuam sendo pequenas. E aqui reside razão para o uso da expressão pequena cidade para aquelas cidades que não são centros locais.

Neste grupo de cidades pode-se encontrar desde aquelas com limite mínimo de complexidade de atividades urbanas, até aquelas onde funções urbanas são mais complexas, refletindo inclusive, diferenças do ponto de vista populacional, manifestando realidades muito distintas (FRESCA, 2001). Desta forma, a autora considera que para se caracterizar uma cidade como sendo pequena, é necessário entender sua inserção em uma dada rede urbana ou região. Precisa-se do "[...] entendimento do contexto sócio-econômico de sua inserção como eixo norteador de sua caracterização como forma de evitar equívocos, e igualar cidades com populações similares, que em essência são distintas" (FRESCA, 2001, p. 28). No momento atual as cidades pequenas e metrópoles, enquanto lugares, são singulares e uma situação não é semelhante a outra, e cada lugar combina de maneira 
particular variáveis que podem ser comuns a vários lugares (SANTOS, 1988). De tal modo que uma cidade pequena na rede urbana de Manaus pode apresentar-se bastante distinta comparativa a uma similar na rede do norte do Paraná, reiterando-se mais uma vez que é a inserção nas redes ou região, que permite melhor caminho para considera-la como pequena.

Por este caminho é possível ter melhores condições de entender uma cidade como sendo pequena, evitando deste modo, as armadilhas das classificações populacionais; das recentes discussões de que o Brasil não é tão urbano quanto se fala, contrariando inclusive análises de Lefébvre (1991) sobre o avanço do urbano na sociedade capitalista; de generalizar que as cidades pequenas são apenas fornecedoras de bens e serviços básicos à população de uma restrita área de influência.

E aqui as contribuições de Corrêa (1999, p. 75-76) auxiliam com algumas possibilidades de interpretação sobre pequenas cidades ao explicar que na etapa atual do desenvolvimento capitalista, ocorreram processos que refuncionalizaram estes núcleos urbanos: mediante perda de atividades e centralidade ou ganhos nos elementos citados; de maior inserção na divisão territorial do trabalho via produção industrial. Para o autor

[...] As transformações verificadas no campo alteraram o padrão desses pequenos lugares centrais, criando pelo menos quatro caminhos ao longo dos quais evoluíram: I - Prósperos lugares centrais em áreas agrícolas nas quais a modernização não afetou radicalmente a estrutura fundiária e o quadro demográfico [...] II - Pequenos centros especializados. [...] III - Pequenos centros transformados em reservatórios de força de trabalho ou que assim nasceram [...] IV - Pequenos centros em áreas econômica e demograficamente esvaziadas por um processo migratório que desequilibra ainda mais uma estrutura etária, afetando ainda a proporção dos sexos (CORRÊA, 2004, p. 75-76).

É preciso considerar para tanto, o nível do desenvolvimento das forças produtivas e das relações sociais na formação social brasileira de modo a entender que

[...] o processo modernizador não se realiza da mesma forma em todos os lugares. Tem-se que, nas pequenas cidades, ele se poderia apresentar mais residualmente. Contudo, enquanto tal, de modo imanente, o processo do capital põe as diferenças temporais e espaciais: formas pré-capitalistas de produção ou não capitalistas o tempo todo são reproduzidas, simultaneamente, ao modo de produzir especificamente capitalista. A divisão social do trabalho se desdobra numa divisão territorial do trabalho, em que momentos diferentes do processo estão se realizando em diferentes lugares, pondo, assim, diferenças sociais e econômicas [...] a análise é a da simultaneidade dos processos implicados, enquanto as temporalidades e espacialidades diversas são tidas como inerentes [...] (DAMIANI, 2006, p. 137).

Tendo em conta que o desenvolvimento se realiza heterogeneamente, é necessário acrescentar outros caminhos de alterações nas pequenas cidades, que diversos estudos tem demonstrado mediante a perspectiva teórica de que é na compreensão das mudanças na formação social de cada área ou região brasileira e da maneira como ocorrem, que ter-se-á elementos teóricos compatíveis para uma reflexão sobres estas cidades.

As pequenas cidades ainda são responsáveis por atender parcela significativa da população em termos de bens e serviços imediatos à sua população. Mas deve-se considerar que estes apresentam outro caráter qualitativo comparativo a outros momentos históricos. Em outras palavras, os bens e serviços tornaram-se muito mais abrangente em razão das necessidades ou imposições do sistema de consumo à população urbana. Mudanças quantitativas e qualitativas vem ocorrendo no terciário das pequenas cidades, suprindo em parte, demandas de seu mercado consumidor, seja pela presença dos estabelecimentos físicos, bem como pelo comércio via internet. Esta última possibilidade de aquisição de bens, articulado à renda dos consumidores, tem provocado muitas modificações nos anteriores esquemas de análise do terciário.

Da mesma maneira é neste nível de centralidade que se tem as relações mais diretas entre a cidade e a produção agropecuária propriamente dita, estabelecidas a partir da oferta de máquinas, 
insumos, equipamentos, mão de obra qualificada ou não, os sistemas de financiamento agrícola, do sistema de venda da produção, dentre outros. Desta relação emergem inúmeras discussões de como a pequena cidade está inserida em articulações regionais, nacionais e internacionais; de quais mecanismos; de que maneira esta pode ser considerada como uma "cidade do campo" (SANTOS, 1993).

Quando se trabalha com estes questionamentos, é na geografia agrária que encontram-se as maiores referências bibliográficas, discutindo implicações e processos de avanços do capitalismo no campo. Mas, não se tem reflexões de como as pequenas cidades, por intermédio de inúmeras relações, estabelece controle do campo; de qual a participação das mesmas na produção propriamente dita. No momento atual onde amplia-se a produção agroindustrial comandada pelas grandes corporações nacionais internacionais, pequenas cidades são ofertadoras de insumos e mão de obra para esta produção, existindo ainda a possibilidade de haver mecanismos onde haja maior poder e/ ou controle sobre a mesma. As cooperativas, sistema bastante expressivo no Sul do Brasil, coloca-se como um destes mecanismos que consegue até certo ponto, competir com aquelas internacionais, já que tem estratégias bastante expressivas e complexas de atrair seus cooperados. Tem-se aqui uma grande perspectiva analítica para entender as relações entre pequenas cidades e produção agropecuária. Mas não tem havido discussões sobre caminhos através dos quais o meio técnico científico informacional (SANTOS, 1993) se realiza em pequenas cidades articuladas aos agronegócios. Afirma o autor que à proporção em que o campo se moderniza, ocorre uma expansão do consumo produtivo, isto é, o consumo de máquinas, equipamentos, sementes, insumos químicos, dentre outros necessários à produção propriamente dita, cuja demanda é heterogênea segundo os subespaços. "O consumo produtivo rural não se adapta às cidades, mas, ao contrário, as adapta" (SANTOS, 1993, p. 50), podendo-se considera-las como cidades do campo, já que afeiçoadas ao atendimento das demandas do campo. Afirma ainda que

As cidades locais mudam de conteúdo. Antes eram as cidades dos notáveis, hoje se transforma em cidades econômicas. A cidade dos notáveis [...] cede lugar à cidade econômica onde são imprescindíveis o agrônomo (que antes vivia nas capitais), o veterinário, o bancário, o piloto agrícola, o especialista em adubos, o responsável pelos comércios especializados (SANTOS, 1993, p. 51).

Considerando-se que ao desenvolvimento regional se realiza de maneiras muito distintas, quanto maior for a divisão social do trabalho, maiores serão as materialidades e as possibilidades de especialização. Na medida em que o consumo produtivo rural adapta as cidades,

[...] estas são chamadas a dar respostas particulares às necessidades das produções particulares, e daí a maior diferenciação entre as cidades. Estas se diferenciam cada vez mais pelo fato de o nexo do consumo produtivo ser ligado à necessidade de encontrar, no lugar e na hora, respostas indispensáveis à marcha da produção [...] (SANTOS, 1993, p. 56).

Contudo, há que se fazer uma ressalva: se Milton Santos (1982) considera a cidade local como o escalão de menor complexidade na urbanização brasileira, atendendo apenas demandas mais imediatas de sua população, a interpretação acima transcrita, evidencia não tratar-se de cidades locais, mas de pequenas cidades cujas dimensões físico-territoriais, populacionais e controle de parcela da mais valia, por exemplo, são superiores às locais.

É neste sentido que se faz a referência às pequenas cidades e os agronegócios, pois como colocado, não se trata apenas de um tipo particular de atividade agrícola moderna, mas de várias como a soja, o frango, o porco, a cana de açúcar, o leite, onde cada uma tem sua especificidade. Emerge daí uma brutal diferença entre as cidades, posto que o consumo produtivo torna-se cada vez mais diversificado acorde a cada um dos agronegócios. Não seria outra a discussão entre estas pequenas cidades e suas relações com a produção da cana-de-açúcar para álcool ou açúcar. Quais as demandas desta produção em relação às pequenas cidades? Muito pouco já que características de seu cultivo não exige muito insumo, máquinas e equipamentos, etc. Salvo sistema bancário e a força de trabalho para o plantio e corte da cana - os bóias frias - as demandas em relação à cidade

Mercator - volume 9, número 20, 2010: set./dez. 
são muito discretas. Na contrapartida, a produção da soja, milho e trigo exigem elevada diversidade de demandas: insumos, agrônomo, tratorista (para o qual é necessário cursos de treinamento para melhor desempenho dos equipamentos cada vez mais modernos e sofisticados), os escritórios das transnacionais ou cooperativas para efetuarem a comercialização da soja verde, dentre outros. Neste sentido cada um dos agronegócios acabam por suscitar diferentes atividades em cada uma das pequenas cidades, dinamizando-as mais ou menos.

Neste nível de centralidade, pequenas cidades também apresentam um setor industrial que por vezes coloca-se como expressivo no âmbito regional e quiçá nacional para determinados produtos, envolvendo ainda significativa parcela da força de trabalho local e geração de rendas e impostos. Neste sentido algumas cidades podem inclusive serem consideradas como especializadas em certa produção industrial, já que respondem por parcela importante da produção e tem na mesma seu mais importante setor de atividades (VEIGA, 2007; VIETRO, 2006). Aí encontra-se uma das questões para ser discutida, pois as análises da produção industrial tem sido na geografia, ainda tratada basicamente para as áreas metropolitanas e mais recentemente para as denominadas cidades médias, enquanto as pequenas cidades não tem recebido maior atenção. Isto não significa que seja neste grupo de cidades que se encontram as maiores produções ou mais importantes do ponto de vista da geração de empregos ou inovações, dentre outras. Mas nelas ocorre uma parcela da produção que tem sido desconsiderada na análise.

\section{CONSIDERAÇÕES FINAIS}

Diante do avanço contínuo do processo de intensificação da divisão social e territorial do trabalho, entender a dinâmica dos centros locais e pequenas cidades, torna-se importante na medida em que atividades diversas tem sido expandida no território brasileiro. Ressalta-se que a divisão social e territorial do trabalho não se faz igualmente em todos os subespaços nacionais, implicando em que a combinação de fatores como demografia, modernização da agricultura, transporte, retenção de mais- valia, indústria, etc. “[...] dá o nível da urbanização e sua geografização, nos dá o padrão de distribuição das cidades, a forma de sua rede urbana, assim como o 'perfil urbano' de um país, isto é, o tamanho respectivo das cidades dentro de um sistema” (SANTOS, 1982, p. 38). Acrescente-se ainda que em cada etapa da divisão do trabalho, altera-se qualitativa e quantitativamente as atividades realizadas pelas cidades, impondo pesquisas mais sistemáticas sobre esta temática.

\section{REFERÊNCIA BIBLIOGRÁFICA}

CORREAA, R. L. Globalização e reestruturação da rede urbana: uma nota sobre as pequenas cidades. Território, Rio de Janeiro, n. 6, p. 43-53, jan/jun. 1999.

CORREAA, R. L rede urbana: reflexões, hipóteses e questionamentos sobre um tema negligenciado. Revista Cidades, Presidente Prudente, v. 1, n. 1, p. 65-78. jan./jun. 2004.

DAMIANI, Amélia Luisa. Cidades médias e pequenas no processo de globalização: apontamentos bibliográficos. In: GERAIGES, A. I. L.; ARROYO, M. ; SILVEIRA, M. L. (Org). América Latina: cidade, campo e turismo. São Paulo, CLACSO, 2006.

ENDLICH, A. M. Pensando os papéis e significados das pequenas cidades no noroeste do Paraná. 2006. Tese (Doutorado em Geografia) - FCT/UNESP, Presidente Prudente.

FRESCA, T. M. A dinâmica funcional da rede urbana do oeste paulista: estudo de casos: Osvaldo Cruz e Inúbia Paulista. 1990. Dissertação (Mestrado em Geografia) - Centro de Filosofia e Ciências Humanas da Universidade Federal de Santa Catarina (UFSC), Florianópolis.

FRESCA, T. M. Em defesa dos estudos das cidades pequenas no ensino de geografia. Geografia, Londrina, vol. 10, n. 01, p. 27-34, jan/jun. 2001.

IBGE. Regiões de influência das cidades 2007. Rio de Janeiro: IBGE, 2008. 
LEFEBVRE, Henri. O direito à cidade.São Paulo: Moraes, 1991.

MELO, Nágela A. Pequenas cidades da microrregião geográfica de Catalão (GO): análises de seus conteúdos e considerações teórico-metodológicas. Tese (Doutorado em Geografia) - UFU , Uberlândia.

OLANDA, Elson Rodrigues. As pequenas cidades e o vislumbrar do urbano pouco conhecido pela geografia. Ateliê Geográfico, Goiânia-GO v. 2, n. 4 , agos/2008, p.183-191.

OLIVEIRA, B. S.; SOARES, B. R. O papel das cidades locais no Triângulo Mineiro e Alto Paranaíba (MG) no contexto regional. Revista Horizonte Científico, PROPP/UFU, Uberlândia, 2003. < Disponível em: $<$ www.ufu.br/revistahorizontecientifico $>$.

SANTOS, M. Espaço e sociedade: ensaios. Petrópolis: Vozes, 1982.

SANTOS, M. A urbanização brasileira. São Paulo: Hucitec, 1993.

SANTOS, M. Metamorfoses do espaço habitado: fundamentos teóricos e metodológicos da geografia. São Paulo: Hucitec, 1988.

SOARES, Beatriz Ribeiro. Pequenas e médias cidades: um estudo sobre as relações socioespaciais nas áreas de cerrado em Minas Gerais. In: SPOSITO, Maria Encarnação B. Cidades médias: espaços em transição. São Paulo: Expressão Popular, 2007. p. 461-494.

VEIGA, L. A. Jaguapitã: pequena cidade da rede urbana norte paranaense especializada na produção industrial de mesas para bilhar. 2007. Dissettação (Mestrado em Geografia, Meio Ambiente e Desenvolvimento) - Universidade Estadual de Londrina, Londrina.

VIETRO, A. F. O processo de industrialização de Apucarana - PR: a capital nacional do boné. 2006. Monografia (Bacharelado em Geografia) - UEL, Londrina.

WANDERLEY, M. de Nazareth B. Urbanização e ruralidade: relações entre a pequena cidade e o mundo rural: estudo preliminar sobre os pequenos municípios em Pernambuco. $<$ Diponível em: http://www.fundaj. gov.br/observanordeste/obed001f.html>. Acesso em 12 abril 2010.

Trabalho enviado em setembro de 2010 Trabalho aceito em dezembro de 2010 